\title{
Conservation and Inheritance of Gansu Red Architectural Cultural Heritage from the Perspective of Landscape Anthropology
}

\author{
Hao Kaili ${ }^{1,}$ a, Shi BoYuan ${ }^{2, b^{*}}$ \\ ${ }^{1}$ Department of Environmental Design, Lanzhou Jiaotong University, Anning, Lanzhou, Gansu, China \\ ${ }^{2}$ College of Innovation and Entrepreneurship, Lanzhou Jiaotong University, Anning, Lanzhou, Gansu, China \\ ae-mail: 1695708419@qq.com \\ $b^{*} e$-mail:119258555@qq.com
}

\begin{abstract}
Landscape anthropology is a new branch of overall anthropology. It systematically studies the multi-culture, form, nature and structure of landscape by using the research perspective, comparative method and field investigation of landscape anthropology, aiming at exploring the interaction and influence between human and landscape places and landscape space. After analyzing the red architectural cultural heritage in Gansu, with the help of the research direction of landscape anthropology, we can find the current status of the protection and inheritance of the red architectural cultural heritage in Gansu from different research perspectives, and analyze the characteristics of the red architectural cultural heritage represented by Gansu in northwest China. From the perspective of landscape anthropology, this paper discusses the problems existing in the protection and inheritance of gansu's red architectural cultural heritage, so as to put forward strategies and suggestions for the protection and inheritance of Gansu's red architectural cultural heritage.
\end{abstract}

Keywords: landscape anthropology, Gansu red architecture, cultural heritage, protection, inheritance

\section{景观人类学视角下甘肃红色建筑文化遗产的保护与传}

\section{承}

\author{
郝凯利 $1, \mathrm{a}$ ，史博源 $2, \mathrm{~b}^{*}$
}

1 环境设计系, 兰州交通大学, 安宁, 兰州, 甘肃, 中国

2 创新创业学院, 兰州交通大学, 安宁, 兰州, 甘肃, 中国

ae-mail:1695708419@qq.com

$b^{*}$ e-mail:119258555@qq.com

\section{摘要}

景观人类学是整体人类学的一个新型分支, 利用景观人类学的研究视角、比较方法以及田野考察工作对景观的 多元文化、形态、性质和结构等做出系统地研究, 旨在探求人与景观场所、景观空间的相互作用和影响。在对 甘肃红色建筑文化遗产做出分析后, 借助景观人类学这一研究方向, 可以从不同的研究角度找到当前甘肃红色 建筑文化遗产在保护与传承方面现状, 分析西北地区以甘肃为代表的红色建筑文化遗产的特点, 并从景观人类 学的视角研究探讨当前甘肃红色建筑文化遗产的保护与传承过程中存在的问题, 从而针对性地提出对甘肃红 色建筑文化遗产的保护与传承的策略和建议。

关键词: 景观人类学 甘肃红色建筑 文化遗产 保护 传承 


\section{1.前言}

20 世纪 90 年代以来, 由英国、美国等国最先研 究探讨的人类学领域, 出现了一个新型词汇 “景观人 类学”, 这一词汇引起了国内外学者的热议, 与人类 学理论相似, 但又区别于人类学。根据 Eric Hirsh 的 观点, 景观人类学的 “景观” 指人类对环境的主观性 认知和看法 ${ }^{[1]}$ 。也就是说, 无论是在同一个生态环境 还是不同的环境, 人类都会按照集体记忆中共有的特 性来认知和感受自然环境与周围的建筑文化等。在这 里, 针对集体记忆, 我们可以推溯出两个部分, 一是 当地人在此生活后对环境积累出的认知、嵌入的历史 记忆、社交网络等; 二是外部观察者对认知到的环境 做出的反应与记忆以及政府权利的分割, 他们同时关 注并描绘所看到环境的文化意象和景观意象。

日本学者河合洋尚认为: 在景观人类学中, 前者 (外部观察者) 的行政区域被称为 “空间”, 后者 (当 地人）的生活场域被称为 “场所”, “空间” 和 “场所” 成为景观人类学的主要分析框架 [1]。依托此主体框架, 我们逐渐明了讨论的问题有三点:一是作为 “局外人” 如何对 “空间”产生的景观意象引发共鸣并塑造认知; 二是作为当地人如何在生活场域找到真正的文化认 同感并将这种感知到的东西保留并传达出去; 三是在 实际的景观建设中如何融入以上种种带有人文批判 性的文化意象，进而丰富场所精神。

在现代科技发展的今天，不同层次的人所经历的 事和人也是不尽相同的, 在各自格局下对相同的环境 和建筑等都会产生不同的感受; 相较于乡村, 居住在 都市的人随着现代文明不断渗透, 对田园化生活与环 境有着浓浓的向往之情, 面对冰冷等入云间的闪闪大 楼, 更能留住 “乡愁” 的反而是低矮的乡村建筑与田 野池塘。当前的学科领域研究中大多学者关注于对 “局外人” 的空间研究, 对于当地人就 “场所” 的描 述我们反而忽视了。本文研究景观人类学旨在着重关 注 “场所” 记忆一一历史记忆与社交记忆等的过程。

\section{2.甘肃红色建筑文化遗产的定义、类型及价 值研究}

\section{1 红色建筑文化遗产定义}

红色文化遗产就字面定义来说, 红色文化遗产与 革命旧址概念较为相似, 革命旧址主要是指近现代经 历过由中国共产党领导的新民主主义革命, 并体现革 命精神或文化的各种附属物, 具体有重要机构和重大 会议会址、名人故居、重大战役遗址、纪念物或为记 录革命历史而修建的各种纪念碑(塔、堂)及其他纪念 性建筑 ${ }^{[2]}$ 。是中华文明极致珍贵的精神宝藏, 和不同 时期的文化遗产一样, 红色文化遗产具有不可再生的 特性，在当代文化遗产的保护中绝不可小嘘它的价值。 红色建筑遗产顾名思义是红色文化遗产的一部分, 其 关注点着重在建筑物及建筑群上, 在这里, 文章将红
色建筑文化遗产定义在中国共产党成立至解放前的 28 年间，包括革命人物故居、政府机关等其他相关革 命的具有宝贵研究价值的构筑物。习近平总书记强调: “要把红色资源利用好、把红色传统发扬好、把红色 基因传承好。”因此, 我们有义务响应总书记的号召, 保护红色文化遗产，推动文化绵延传承。

\section{2 红色建筑文化遗产类型研究}

甘肃红色建筑文化遗产除了土地革命、抗日战争、 解放战争以及社会主义革命时期的建筑遗存外, 还包 括能够反映革命精神传承延续的新时代建设遗产, 例 如三线建设遗产、改革开放遗产等。对甘肃的红色建 筑文化遗产资源类型进行梳理, 目前得出包括革命遗 址遗迹、革命故居、旧居住址、革命纪念建筑物、纪 念碑、纪念亭、烈士墓祠、烈士墓碑等。

\section{3 甘肃红色建筑文化遗产研究价值}

首先在物质本体方面, 红色建筑文化遗产是我们 更好的研究红色文化的载体, 因城市化与红色建筑文 化遗产之间的矛盾加剧, 甘肃省内红色建筑及其周边 的历史环境遭到了不同程度的破坏，这种保护意识的 薄弱反映出人们对红色建筑遗产的认同感和文化自 信在不同层面都有所缺失，强化文化载体有助于唤起 人们的社会记忆、历史记忆，有利于激发人们的革命 精神，为我们留下追溯先烈的宝贵考察资料。

其次在时间方面, 红色建筑文化遗产是国人在长 期的革命中留下的“活的灵魂”，人民赋予了建筑精神 内核, 对红色建筑遗产长久的复原与保护才能深化个 人对红色历史的集体记忆。红色建筑文化遗产的历史 价值和特定的时间是相关的, 它反映的是那个特殊时 代背景下建造的风格形式和目的。随着历史的沉积， 时代的变迁给予了这些建筑年代感和空间上的沧桑 感。

再次是环境功能方面, 建筑的构建在某种层面都 是为了满足人类生产生活的空间, 因此, 建筑的功能 价值是经由人类长期使用中赋予的。甘肃红色建筑遗 产的环境功能价值在于它诞生在那些特定的红色年 代中并被所处环境中的人所使用过程中激活, 在外部 环境的影响下建筑的外形结构也会发生变化, 从而反 映当地的地域特色、生活习惯及历史文脉。

最后是情感介入方面, 甘肃红色建筑遗产在红色 历史延续、民族自豪感和认同感等方面发挥积极作用。 通过建筑凝聚当地的历史文化和红色精神, 这些精神 共筑了国家的共同情感基础，能够燃起人民对红色文 化的认同感和对国家文化的自信心和归属感。由个人 记忆涌向集体记忆最终形成地区记忆和国家记忆。

\section{3.甘肃红色建筑遗产的特点}

甘肃省地处青藏高原、黄土高原和内蒙古高原的 交汇地界, 地形的复杂造就它兼具三大自然区的地理 
特征，在革命进程中，甘肃也有着不可小觑的历史地 位。习近平总书记在 2019 年 8 月于甘肃考察中讲话: “甘肃是一片红色土地, 在中国革命历史进程中发挥 了不可替代的重要作用。”在这片红色大地上, 中国共 产党人留下了可歌可泣的红色篇章和不可泯灭的红 色烙印。甘肃红色建筑作为载体, 存在于红色文化遗 产中有着重要的地位, 甘肃红色建筑遗产特点可以概 括为两大个方面。

第一, 甘肃红色建筑大多追求实用朴素, 这和中 国共产党人的信仰密不可分。在具体设计中, 主要分 为窑洞、土坏建筑等, 在具体构造中既可以省下不少 经费, 又能保证房间室内温度稳定, 在草泥墙上多半 开小窗通风, 这样的建筑在冬季有利于保暖, 夏季又 可以通过隔热来降温, 在地处西北的甘肃这种建筑非 常适用。

第二, 甘肃红色建筑结构简单, 但却很牢固。在 建造房屋的时候, 往往采用的是最典型的构造方式, 纯天然的、干燥的土坏砖是由粘土, 草泥混合在一起 用手工在模型中制造的。与常规的建筑材料相比, 这 种依地理位置应运而生的材料具有可再生性, 房屋拆 除后材料可反复利用, 甚至可作为肥料回归农田。并 且土坏建筑施工起来简单快捷, 工程造价也是十分低 廉。

\section{4. 甘肃红色建筑文化遗产的现状探析及保护 与传承问题}

当前国内学者从景观人类学的角度对于甘肃红 色建筑文化遗产的相关研究成果较少, 大多学者还是 基于城市规划、建筑学等角度进行反复探讨。景观人 类学的分析视角和以往其他研究有所不同, 在研究中 更注重实践一一田野考察, 通过对当地风俗、环境、 发展、习惯, 居民生活的走访等方面进行研究整合, 拼合出当地居民对环境长期累积的集体生活记忆。最 终通过景观的手段在解构当地生活场景的同时透过 社会学、场所精神论和建筑学结合来进行分析, 从而 探究红色建筑遗产在甘肃这片土地上的生长意义。

因此，对于甘肃红色红色建筑遗产的保护，我们 不能单一的从某个角度切入, 而是应该多学科交叉研 究, 从建筑文化, 城乡规划学等方面综合探析, 对建 筑的保护与传承是一件持续跟进并长久存在的事, 当 前研究现状中对甘肃红色建筑文化遗产的保护利用 及开发传承上存在很多方面的不足。

\section{1 科技的迅速蓬勃无法完全带动甘肃红色建 筑文化遗产的复兴}

科技的进步推动社会各种力量的迅速发展, 这对 文化的传承起到保护作用, 但对于红色性质的文化单 凭科技途径是无法起到传承力量的。这也正是当代社 会依靠互联网所带来的副作用。我国大多数文化遗产 受国家保护的同时被开发出供大众旅游, 带动周边经
济; 利用科技手段对建筑文化遗产进行数字展示、保 护与修复。但是这种长久性的数字记忆究竟为我们留 下了什么, 一串串数字构成的记忆中缺少了我们自身 对建筑遗产的社会记忆, 人们通过数字影像观看过去 与未来, 一眼数年, 数字只会增加不会变少, 但却在 大脑中停留不过几天就会遗忘, 因为这其中缺少了我 们对建筑本身的切身感受。因此, 要想真正的保护与 推广古建筑好需要全社会共同的努力, 数字化只是其 中的一种手段和技术, 以数字化为落脚点, 深入研究 和探讨数字化技术在古建筑中的应用 ${ }^{[3]}$ 。

\section{2 城乡一体化进程下建筑体同质化和表面化}

随着城市化进程的不断推进，坐落于甘肃不同地 县的红色建筑文化遗产都不可避免收到波及, 传统的 红色建筑越来越与周边的高楼大厦和中西结合的小 洋楼格格不入。慢慢的时间流逝, 这些建筑文化遗产 在得不到重视的情况下也会逐渐消失。

在此过程中，还出现另一种现象，后期改造的红 色建筑出现了同质化和敷于表象的问题。这种问题不 止出现在建筑载体上, 更是在很多文化延传上也发生 了一些变化, 由于没有针对各个地域红色建筑文化遗 产的保护措施, 并且随着当地居民对居住环境的贴近 城市化迫切需求, 特别是一些长期在外打工的人, 对 于外界文化和建筑风格的认同大于本土建筑, 所以就 会出现一些与传统文化相抵触的现代建筑 ${ }^{[4]}$ 。导致一 些体现本土化精神的红色建筑正在消失。虽然国家对 红色文化遗产也进行了保护，但是往往保护的同时是 对资源的无限开发, 这种重表象而不注重内在文化的 传承在短期是有用的, 但长此已久问题就会暴露。被 同质化和表象化的风险也会随之增加。

\section{3 红色文化的传承力度不够，人民对红色建 筑遗产缺乏民族文化自信}

文化自信的培养需要文化载体媒介传承, 红色建 筑遗产的保护对传承红色文化至关重要, 但是随着人 们对红色文化的陌生使得这些建筑遗产缺乏后期人 们赋予的文化基础。景观人类学视角下甘肃红色地区 居民生活习俗和地域文化的保护与传承, 所形成的独 有的建筑构造和规划布局, 在当中蕴含了很多当地文 化符号。但是随着经济的增长, 越来越多当地年轻人 外出寻求出路, 对于本土文化往往都遗忘有余, 红色 建筑文化遗产的不完全正确开发导致人们对建筑遗 产缺乏民族文化自信感和认同感。加之区域地县的建 筑施工队都缺乏保护传承的意识, 这种种造成甘肃红 色建筑文化遗产在传承上出现断层现象。 


\section{5.对甘肃红色建筑文化遗产保护与传承的建 议}

\section{1 国家层面加强对红色文化遗产中构筑物的 保护，突出对红色文化的整合提炼}

在对于传统文化和规则保护上, 尤其是对于建筑 这类景观人类学的保护上, 可以通过完善相应的法律 法规来进行保护，并敦促地方政府出台相应的保护当 地文化及建筑的地方性法规精髓文化予以保留, 这些 都是国家层面应当予以考虑的 ${ }^{[4]}$ 。通过国家层面对建 筑文化遗产的保护，突出红色文化的传承，在政府统 一改造规划的过程中, 尽最大可能将建筑遗产融入到 周边环境中, 使其不唐突的同时增加当地文化特色, 政府在下达政策时应该重视景观人类学的理念, 关注 技艺的传承。

\section{2 激发居民对红色建筑文化遗产的保护与传 承}

从景观人类学的视角来看, 甘肃红色建筑文化遗 产是由特殊时期革命者留下的, 经过后期当地居民生 产生活后自发产生的社会记忆, 这些记忆和外来游客 所产生的想法感受是有区别的, 因此对于甘肃红色建 筑文化遗产的传承应由当地居民主导进行。合理的将 遗产保护和居民利益达到平衡, 激发当地居民的保护 欲。

随着居民生活需求的提高, 乡村逐渐成了“空城”, 留守的大多是老人和孩子, 可见政府给予乡村的补贴 达不到他们的生活要求。如果能将这些红色文化建筑 加以保护开发利用, 往往可以取得意想不到的效果, 既能活跃地区文化内涵, 又能在经济利益上解决居民 困顿, 形成集文化传承保护和利用开发为一体的产业 链。今后的研究, 不仅要关注 “静态” 的建筑文化遗 产, 也要俯下身去倾听围绕着它们的种种话语和被淹 没的 “声音” [5]。

\section{3 合理的融入科技元素，进行红色文化旅游 开发}

地方政府应当借助科技手段对甘肃红色建筑遗 产存档收录, 对于一些即将消逝的建筑遗产要及时修 复, 加强保护力度。从景观人类学角度考虑, 加强外 部因素, 如加强对外来游客的讲解, 增加他们的保护 意识; 对红色建筑的周边景观应当进行合理规划再设 计, 景观是服务于建筑的, 更是衬托建筑主体的要素, 合理的融入一些科技景观, 有助于吸引游客眼球, 从 而带动旅游业的开发。尽可能遵循保护自然生态的原 则，不破坏建筑遗产原有的形式和韵味。

\section{6.总结}

截止目前, 甘肃红色建筑文化遗产还没有被完全
开发, 各个红色旅游景点也只是大多从利益的角度出 发考虑, 这种结构单一化的保护对文化遗产的传承作 用收效甚微。因此我们更应该多角度多学科出发探究 建筑的保护性和传承性。通过对 “场所” 和 “空间” 的共同研究, 相互配合, 遵守以人为本的原则, 将红 色土地上人民的生活经验、历史记忆等通过红色建筑 载体表达出来。加之政府对旅游业的大力开发, 相信 在不久的将来, 甘肃红色建筑文化遗产会得到重视与 保护的。

\section{项目基金:}

本文为甘肃省科技厅计划项目-甘肃红色 建筑文化遗产资源保护与可持续演进途径研 究 (21CX6ZA071) ; 兰州交通大学青年科学 基金项目-基于线性文化遗产概念下长征（甘 肃段）的保护与开发策略研究（2021042）的 阶段性成果之一。

\section{REFERENCES}

[1] He He Yang Shang. Hakka architecture and Cultural Heritage protection from the perspective of landscape anthropology [J]. Academic Research, 2013 (04) : 55-60.

[2] Xue Qian, XUE Liyao. Research on protection planning method of revolutionary old sites based on original environmental features: A case study of Yangjiagou in Northern Shaanxi [C]. Chinese Society of Landscape Architecture. Proceedings of the Annual Conference of Chinese Society of Landscape Architecture ,2019 (Volume 1), 2019:6.

[3] Wu Nan, Wu Chuhao. Digital protection and promotion of ancient buildings [J]. Intelligent Building and Smart City, 2020 (11) : 139-140.

[4] Wang Pingyu. Conservation and inheritance of Tujia Architectural Landscape Culture in Southeast Chongqing from the perspective of landscape anthropology [J]. Guizhou ethnic studies., 2018,39 (12).

[5] $\mathrm{Wu}$ Tianyue. "Landscape Anthropology" and "Regeneration" perspective: A Review of Japanese anthropologists' Research on Chinese Hakka Architecture -- A Case study of Kahe Yosho and Kobayashi [J]. Natural and cultural heritage research, 2020,5(04). 